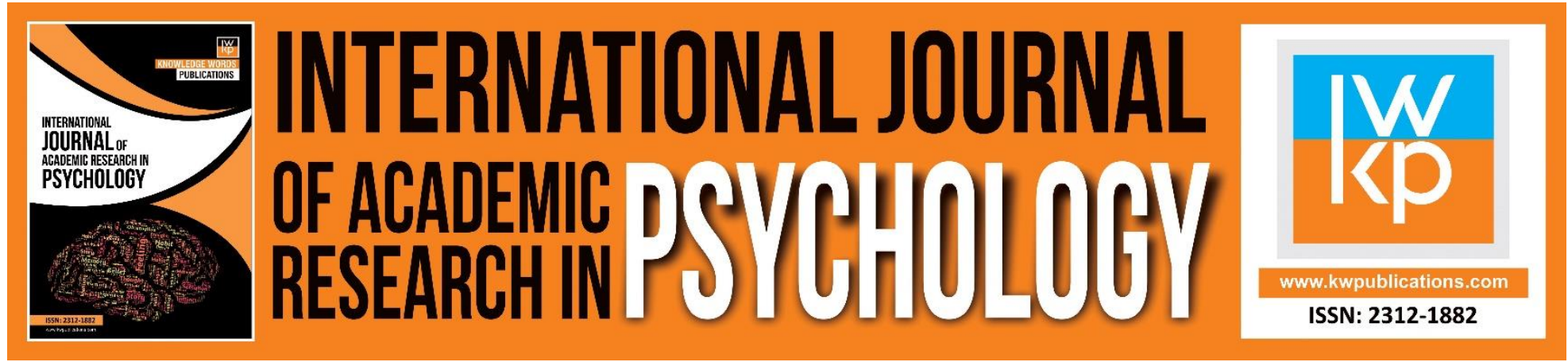

\title{
Effect of Gender on the Psychological Wellbeing of Nurses in Enugu Metropolis
}

\author{
O. J. Okeke, Chiamaka P. Okeke
}

To Link this Article: http://dx.doi.org/10.46886/IJARP/v5-i1/7306

DOI: $10.46886 /$ IJARP/v5-i1/7306

Received: 08 January 2018, Revised: 13 February 2018, Accepted: 16 March 2018

Published Online: 26 March 2018

In-Text Citation: (Okeke \& Okeke, 2018)

To Cite this Article: Okeke, O. J., \& Okeke, C. P. (2018). Effect of Gender on the Psychological Wellbeing of Nurses in Enugu Metropolis. International Journal of Academic Research in Psychology, 5(1), 1-9.

\section{Copyright: (c) 2018 The Author(s)}

Published by Knowledge Words Publications (www.kwpublications.com)

This article is published under the Creative Commons Attribution (CC BY 4.0) license. Anyone may reproduce, distribute, translate and create derivative works of this article (for both commercial and non-commercial purposes), subject to full attribution to the original publication and authors. The full terms of this license may be seen at: http://creativecommons.org/licences/by/4.0/legalcode

$$
\text { Vol. 5, No. 1, 2018, Pg. } 1 \text { - } 9
$$

Full Terms \& Conditions of access and use can be found at https://kwpublications.com/pages/detail/publication-ethics 


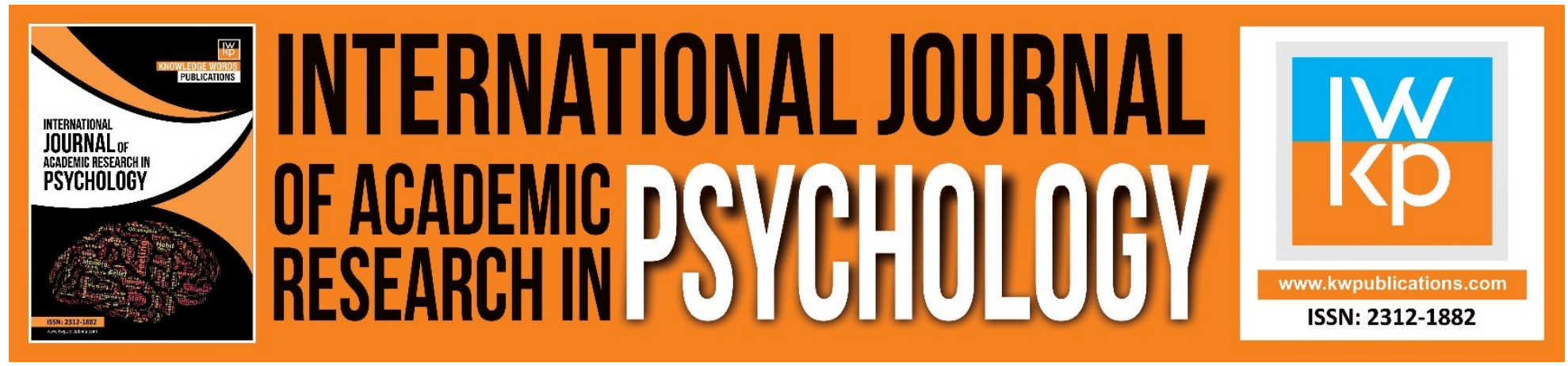

\title{
Effect of Gender on the Psychological Wellbeing of Nurses in Enugu Metropolis
}

\author{
O.J Okeke (Ph.D) \\ Department of Chemistry Education, School of Science Education, Enugu State College of \\ Education (Technical) Enugu, In Affiliation to Nnamdi Azikiwe University Akwa
}

\section{Chiamaka P. Okeke}

Department of Psychology, Ebonyi State University, Abakaliki

\begin{abstract}
This study examined Gender as a predictor of psychological wellbeing of Nurses in Enugu Metropolis. The design of the study used is Cohort. The area of the study is Enugu Metropolis. The population of the study is Two hundred and fifty (250) Nurses. The sample and sampling technique used are two hundred and fifty purposively selected. The instruments used to collect data was Warwick Edinburgh Mental Wellbeing scales. This indicated responses from the two hundred and fifty (250) Nurses. The instruments were validated by three experts, two from measurements and evaluation and one from psychology education. ANOVA was used to analyze responses from participants. Results show that gender did not predict psychological wellbeing among Nurses. Result indicated that gender did not predict psychological wellbeing with $(\beta=-0.2, t=-0.31)$. This clearly agrees with the hypothesis that gender will not significantly predict psychological wellbeing among Nurses. Hence the hypothesis which stated that gender has no significant impact on the psychological wellbeing of nurses in Enugu Metropolis was confirmed.
\end{abstract}

Keywords: Gender, Psychological, Wellbeing, Nurses.

\section{Introduction}

Every nation aims for higher standards in psychological well-being and health care, which thus implies ongoing changes and health reforms around the world. Psychological wellbeing is considered as a balance between positive effect and negative effect. Positive wellbeing is an appraisal of the status of one's functioning and outcome along several distinct but interrelated dimension including global, mental and physical healthfulness. According to Longman Dictionary of Contemporary English (2017) Psychological well-being is a positive state of physical, mental and social well-being. It is not merely the absence of disease or infirmity.

Sominen et al., (2000), emphasized on physical processes and advocate focusing on the connection between good physical health and high quality of life. Epstein (1992); Ingram and Wisnick (1998); Martin and Rubin (1995); Stephen, Dulberg and Joubert (1999) described psychological well-being more as a cognitive process that emphasizes life satisfaction as the 
key indicator of wellbeing. Others propose that wellbeing entails spiritual processes such as purposefulness in life, which leads to optimal functioning (Adams, Bezner and Steinhardt, 1997; Ellison, 1983; Ryff and Singer, 1998). Self and social processes, such as possessing positive self-regard and self-mastery and, secondary, quality self-regard and, secondary, quality and meaningful connections to others, are also proposed (Adams et al, 1997; Costa and McCrae, 1992; Pretorius, 1998; Roid and Fitts, 1989; Ryff and Singer, 1998; wegner, schwarzer and Jeruselem, 1981/1993). Consequently, it would seem that psychological wellbeing can be conceptualized with reference to physical, cognitive, spiritual, self and social processes.

Current studies on the existence of gender differences, including those related to psychological wellbeing reflect contradictory result and a distinct lack of consensus (Ryff and Singer, 1998; Strumpfer, 1995). Gender differences in psychological wellbeing are important because of the many efforts being made in contemporary society to empower all individuals to achieve self-actualization and utilize their full potential. In a post-feminist context this incorporates the idea of an "equal opportunities" society; yet social stereotypes still remain (Connors, 1990; Eagly, 1987; Turner and Sterk, 1994). All people are but not identical, and the possible differences between need to be considered in order to empower all individuals to achieve self-actualization and to fulfil their potential (thereby promoting optimal psychological wellbeing), whilst being offered equal opportunities.

Based on previous studies and qualitative experiences, (Crose et al., 1992) believe that gender differences do exist in almost every aspect of health and health care. In a Taiwanese study, Lu (2000) discovered gender differences while examining conjugal congruence on role experiences and psychological wellbeing, while (Stephens, Dulberg and Joubert, 1999) found gender differences in a study examining mental health in the Canadian population. Marks (1996) also found differences in her Wisconsin study, but ascribed these primary to marital status, which interacts with gender, rather than to gender differences.

Nurses occupy a central role in the delivery of health care, though countries may have different health care systems and methods of payment options. Unfortunately, research conducted in various countries has indicated that levels of nurse dissatisfaction, burnout and intent to leave the profession are high. Younger individuals are also less interested in careers in nursing, especially the male gender. Some countries are now reporting a shortage of nurses, often compounded by the fact that richer nations are luring nurses away from poorer ones. The health care system has also undergone significant change over the past decade stemming from the greater use of new technologies, offshoring some services to developing countries, advances in medical knowledge, an aging population, more informed and critical users of the health care system, and efforts by governments to further control health care expenditures. Nursing appears to be a crisis. This if not taken care of can lead to high rate of death and pose serious health challenges to a country. This nonchalanncy in pursuit of nursing profession and inadequancies in among nurses has prompted this research to examine the effect of gender on the psychological wellbeing of nurses in Enugu Metropolis.

\section{Objective of the Study}

The objective of the study is to investigate whether gender will determine psychological wellbeing among nurses.

\section{Research Question}

To what extent does gender influence the psychological wellbeing among nurses in Enugu Metropolis? 


\section{Hypotheses}

The hypothesis postulated and tested in the course of this study is thus:

$\mathrm{H}_{0}$ : Gender has no significant impact on the psychological wellbeing of nurses in Enugu Metropolis

\section{Literature Review}

\section{Gender and psychological well-being}

Gender refers to the cultural differences expected (by society / culture) of men and women according to their sex. A person's sex does not change from birth, but their gender can. In the past people tend to have very clear ideas about what was appropriate to each sex and anyone behaving differently was regarded as deviant. Today we accept a lot more diversity and see gender as a continuum (i.e. scale) rather than two categories. So men are free to show their "feminine side" and women are free to show their "masculine traits". The biological approach suggests there is no distinction between sex \& gender, thus biological sex creates gendered behavior.

Brett. Doret, \& Marie, (2003) conducted a study which is on research initially obtained for FORT project (a trans-university research programme on fortology; clarification and enhancement of psycho-social well-being), A snowball method of sampling was used and 378 participants were used and each completed a 13 scale that measures psychological wellbeing in affective, cognitive, spiritual, self and social -aspects. The aim of the study was to determine whether significant gender differences exist with regard to affective, physical, cognitive, spirit mil, self and social of psychological, wellbeing. The study indicates some differences in self-evaluated psychological wellbeing of men and women. Men scored significantly higher on cognitive, physical and self-aspects, and women scored significantly higher on somatic symptoms, the expression of and spiritual aspects. No gender differences were found with regards to social aspects or of coherence, affect balance and satisfaction with life, suggesting that the psychological wellbeing of the men and women in this group is comparable, in the study no significant gender differences were found regarding the experience of affect. Men and women perceived themselves as able to gauge and balance then positive and negative emotions, which in turn could their judgment of subjective wellbeing. The result is in line with gender stereotypes, and traditional socialization practices and possibly reflects the impact of longstanding social inequity between men and women.

Dowdy, Dwyer, Smith, and Wallston, (1996) examined a study "the relationship of gender and psychological well-being (PWB) in community-dwelling persons with rheumatoid arthritis", Data from the first wave of two longitudinal studies of persons with RA were examined ( 93 men and 276 women in panel 1; 60 men and 14? women in panel 2), Subjects completed self-report questionnaires on behavioral aspects of RA, Psychological wellbeing was assessed in both panels by the Center for Epidemiologic Studies-Depression Scale, using its 4 subcomponents, including positive and negative effect. Panel 2 had additional measures of PWB, namely the Positive and Negative Affect Schedule and the Satisfaction with Life Scale. Potential explanatory variables were then examined in an attempt to account for the observed gender differences.

Gender differences were found for negative indicators of PWB. While positive indicators of PWB showed no significant differences by gender. As with other community samples, women reported higher levels of depressive symptoms and negative mood than men. Quality of emotional support, passive pain, coping and physical functional impairment could only partially explain the observed gender differences in this study. The relationship of gender to negative indicators of PWB cannot easily be diminished or dismissed. The mechanisms by which gender differentially affect PWB need to be further explored in order to intervene appropriately to help men and women with RA achieve an optimal quality of life. 
Perez (2012) conducted a cross sectional, non-experimental quantitative study aimed to determine gender differences in various aspects of psychological wellbeing among Filipino college student. A total of 588 college students from various schools in the Philippines participated in this (males $=110$; females $=478$ ), The participants completed eight scales measuring different aspects of psychological wellbeing. Gender differences were found in terms of daily spiritual experience, relationship, peer relationship, autonomy, positive relations with others, and purpose in life. No gender differences were found in the aspects of positive effect, negative effect, mother relationship, teacher relationship, environmental mastery, personal growth, and self-acceptance.

Akhter S., (2015) conducted a study of psychological well-being among male and female students. The result obtained on the psychology well -being reveals significant difference of girls at: $\mathrm{j}$ boy students. The results indicate that mean and standard deviation of male and female for psychological well-being is 50.5, 4.55 and 5.90, 5.00 respectively, which suggest that there is a difference among male and female on the score of psychological well-being, The .t" value of psychological well-being was 5.68, Therefore, these differences are significant for psychological well-being among the male and female students. According to the t-test the numerical value that we get is 5.68 which is significant at 0.01 level. Therefore the hypotheses that there is significant difference between male and female in psychological well-being is acceptable, it means there is significant difference in psychological well-being among male and female students.

\section{Methodology}

\section{Participants}

Participants in this study were 250 nurses, comprising 42 males and 208 females. Purposive sampling techniques (also known as judgment, selective or subjective sampling) is a sampling technique in which a researcher relies on his or her own judgment when choosing members of population to participate in the study. This technique was used to draw participants from five health institutions in Enugu Metropolis in Enugu State. The participants were nurses of Federal Neuropsychiatric hospital, New Haven, Uwani Cottage Health center Uwani, Poly Sub-District hospital Asata, Federal Orthopedic hospital, and Enugu State University Teaching Hospital, Parklane. Their age ranges from 20-60 years with a mean age of 46.33 .

\begin{tabular}{|l|l|}
\hline Hospitals & Numbers \\
\hline Federal Neuropsychiatric hospital & 59 \\
\hline Uwani cottage Health center & 29 \\
\hline Poly Sub-District hospital, Asata & 35 \\
\hline Federal Orthopedic Hospital & 62 \\
\hline $\begin{array}{l}\text { Enugu State University Teaching Hospital } \\
\text { Parklane }\end{array}$ & 61 \\
\hline
\end{tabular}

\section{Instruments}

Two instruments were used in this study;

The Warwick Edinburgh Mental Well-being Scale, developed and validated by Tennant, Hiller. Fishwick, Platt, Joseph, Welch, Parkinson, Seeker, Stewart-Brown (2007), it was used to access students with the age of $16 y$ ears and above in the UK measuring aspects of mental health involving surveys in both student and general population samples, and focus groups. The scale has 4 items is scored by summing the response to each item answered on a 1 to 5 likert scale with the response as- None of the time, Rarely, Some of the time, Often and All of the time. The minimum scale score is 14 and the maximum is 70 . It has now been widely validated in different 
populations and languages other than English. Some items in the scale include: I've been feeling optimistic about the future; I've been feeling good about myself. The scale has full scale reliability of .83 obtained using Cronbach's alpha coefficient of .\&9. 1 gave the questionnaires to six lecturers who face validated the questionnaires and rated the cronbach alpha high.I gave the questionnaires to six lecturers who face validated the questionnaires and rated the cronbach alpha high.

\section{Procedures}

The questionnaires were administered to 250 nurses from five hospitals in Enugu metropolis; the questionnaires were administered by the researcher to different hospitals on different days. Out of the 250 pies 245 was collected representing a ratio of $98 \%, 10$ copies were discarded due to improper filling leaving a total number of 235 that were used for analysis on this study, 195 females and 45 males. The researcher sought permission from the head of nursing services in the different health institution to administer the questionnaires. The researcher rendered lots of thanks to the participants. Design/Statistics

The study employed a cross-sectional design. The statistics used in this is one way Analysis of Variance (ANOVA)

\section{Result}

Summary of Main Finding

Table 1: Means, standard deviations, and correlations for age, and gender on psychological well

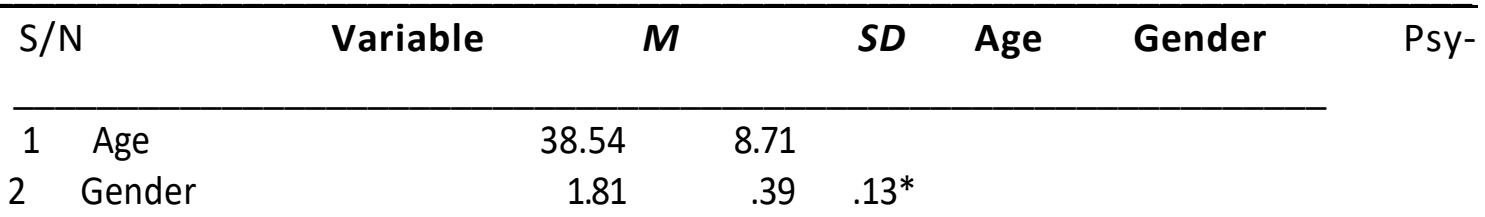

3 Psy-well being $\quad 45.84 \quad 1 * 1.07 \quad-.03 \quad .18 * *$

Note. $N=451,{ }^{*}=p<, 05$ (two-tailed), ${ }^{* *} \sim p<.01$ (two-tailed),). Gender was coded 1 » male, 2 " female; Age was coded in years,

Result of correlation table show that psychological wellbeing was positively significantly related to motivation $(r=.18, p<.01)$; but negatively non-significantly related to age $(r=-$ $.03, p>.05)$ and gender $(r=-.02, p>.05)$. Age was significantly related to gender $(r=.13$, $p<.05)$; Gender was not significantly related to motivation $(r=.09, p>.05)$.

Table 2: Showing the prediction of 'psychological well being' from control variable-age and, gender

$\begin{array}{llllll}\text { R } & \text { R2 } & \text { R2A } & \text { B } & \text { Beta }(p) & T\end{array}$

Model 1

$\begin{array}{lllllll}\text { Age } & .031 & 001 & .001 & -.04 & -.03 & -.48\end{array}$

Model 2

$\begin{array}{lllllll}\text { Gender } & .037 & .001 & .000 & -.52 & -.02 & -.31\end{array}$ 
Table 2 result indicated that the demographic (age) did not significantly predict psychological wellbeing of nurses $(P--.03, t--.48)$. Gender $(B=-.0 .2, t=-.31)$ entered in model two of the equation did not significantly predict psychological wellbeing of nurses. It however accounted for $31 \%$ variance in the explanation of psychological wellbeing of nurses (R2A = $.031, p<.01)$. To find out which gender enjoy psychological wellbeing more among nurse, data obtained from the participants was subjected to a post hoc study in which one way ANOVA was employed. Result of one-way ANOVA indicated that male nurses

$(M=46.33)$ had higher mean of psychological wellbeing than female nurses $(M=46.33)$ (see appendix). The mean plot graph is shown below

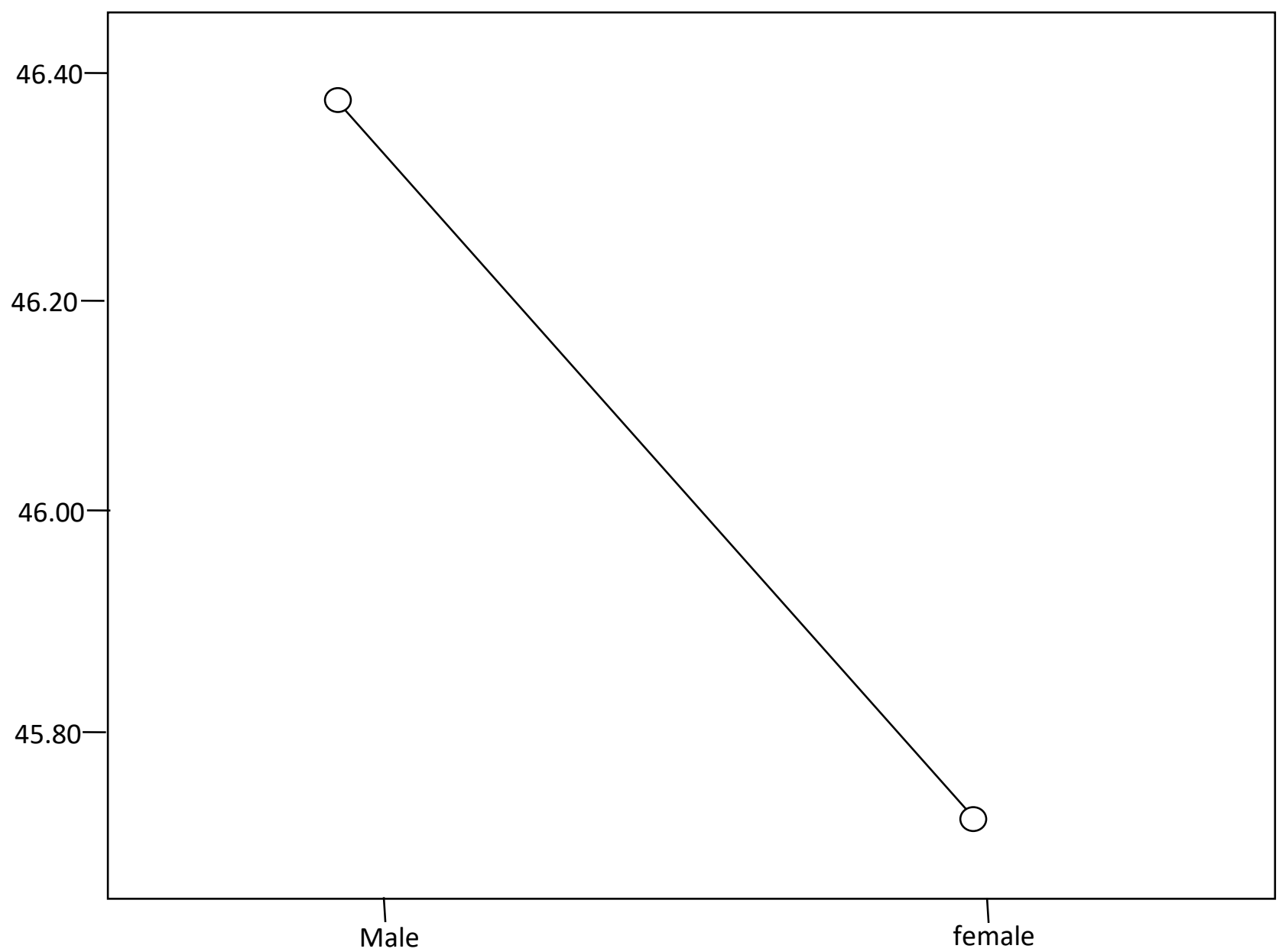


INTERNATIONAL JOURNAL OF ACADEMIC RESEARCH IN PSYCHOLOGY

Vol. 5, No. 1, 2018, E-ISSN: 2312-1882 @ 2018 HRMARS

\section{Discussion}

The result of the study revealed that gender will not statistically significantly predict Nurses psychological wellbeing.Gender enjoy psychological wellbeing more among nurse, using the data obtained from the participants which was subjected to a post hoc study in which one way ANOVA was employed. The Result of one-way ANOVA indicated that male nurses ( $M=46.33$ ) had higher mean of psychological wellbeing than female nurses $(M=46.33)$. This is congruent with that men have higher self-reported levels of ego and cognitive strengths whereas females describe themselves as stronger in social, emotional and spiritual aspects (Bond, Kwan \& Li, 2000; Crose et al., 1992). Morin $\&$ Rosenfield, (1998) proposed that gender differences are encouraged by societal expectations.

\section{Summary and Conclusion}

The findings of the study show that the hypothesis which states that Gender has no significant impact on the psychological wellbeing of nurses in Enugu Metropolis was confirmed. Based on the finding of the study the researcher hereby concludes that there is no significant effect of gender on psychological wellbeing of nurses in Enugu Meytropolis. This implies that the gender of the nurses has no effect on the psychological wellbeing of the nurses in Enugu Metroplolis.

Other studies should be done on gender as a predictor of psychological wellbeing among Nurses. A larger sample should be used with more than five health institutions, as this study focused on five health institutions

\section{References}

Adams, T., Bezner, J., Steinhardt, M. (1997). The conceptualization and measurement of perceived wellness: Integrating balance across and within dimensions. American Journal of Health Promotion, 11(3), 208-218.

Akhter, S. (2015).77ze International Journal of Indian Psychology, 2(4).

Brett, R., Doret, K. K., \& Marie P. W. (2003). Gender Differences in Aspects of Psychological Wellbeing. South African Journal of Psychology, 33 (4), 212-218.

Chukwuneke, F. N., Ezeonu, C. T., Onyire, B. N., Ezeonu, P. O., Ifebunandu, N., and Umeora, M. C. (2012). Health Seeking Behaviour and Access to Health Care Facilities at the Primary Level in Nigeria: Our Experience. Ebonyi Medical Journal, 11, 51-57

Connors, J. V. (1990). Gender differences in perceived advancement problems, stress and satisfaction ofunWersfty. Unpublished doctoral thesis.

Crose, R., Nicholas, D. R., Gobble, D. C., \& Frank, B. (1992). Gender and wellness: A multidimensional systems model for counseling. Journal of Counseling \& Development, 71, 149-156

Dowdy, S. W., Dwyer, K. A., Smith, C. A., \& Wallston, K. A. (1996). Gender and psychological wellbeing of patients living with rheumatoid arthritis. Arthritis care and research 9, (6).

Ellison, C. W. (1983). Spiritual well-being: Conceptualization and measurement. Journal of Psychology and Theology, 11(4), 330-340

Epstein, S. (1992). Constructive thinking and mental and physical well-being. In Montada, L., Filipp, S. H., Lerner, M, J, (Eds), Life crises and experiences of loss in adulthood (pp. 385-409). Hillsdale, New Jersey: Erlbaum

Ingram, R. E., \& Wisnicki, K. S. (1988). Assessment of positive automatic cognition. Journal of Consulting and Clinical Psychology, 56, (6) 898-902

Lu, L. (2000). Gender and conjugal differences in happiness (Electronic version). Journal of Social Psychology, 140(1), 132 
INTERNATIONAL JOURNAL OF ACADEMIC RESEARCH IN PSYCHOLOGY

Vol. 5, No. 1, 2018, E-ISSN: 2312-1882 @ 2018 HRMARS

Longman. (2017). Longman Dictionary of Contemporary English. Retrived from http://www.longman.com/ldoce

Marks, N. F. (1996). Flying solo at midlife: Gender, marital status, and psychological well-being (Electronic version). Journal of Marriage and the Family, 58(4), 917

Martin, M. M., \& Rubin, R. B. (1995). A new measure of cognitive flexibility. Psychological Reports, 76(2), 623-626.

Money, J., \& Ehrhardt, A. A. (1972). Man and woman, boy and girl: Differentiation and dimorphism of gender identity from conception to maturity.

Morin, R., \& Rosenfeld, M. (1998). With More Equity, More Sweat. Retrieved from http://kniiznica.ffzg.unizg.hr/uploads/DuEhOc2AfsxB WVShADHafO/11845115.pdf on the $15^{\text {th }}$ march, 2107.

Perez, J. A. (2012). Gender Difference in Psychological Wellbeing among Filipino College Student Samples. InternationalJournal of Humanities and Social Science, 2(13).

Ryff, C. D. (1989). "Happiness is everything, or is it? Explorations on the meaning of psychological well-being". Journal of Personality and Social Psychology.57: 1069-1081.

Ryff, C. D., \& Singer, B. (1998). The contours of positive human health. Psychological Inquiry, 9(1), 128

Stephens, T., Dulberg, C., Joubert, $\mathrm{ft}$. (1999). Mental health of the Canadian population: A comprehensive analysis (Electronic version). Chronic Diseases in Canada, 20 (3)

Striimpfer, D. J. W. (1995). The origins of health and strength: From 'salutogenesis' to 'fortigenesis'. South African Journal of Psychology, 25, 81-89

Shaywitz, B. A., Shaywltz, S. E., Pugh, K. R., Constable, R. T., Skudlarski, P., Fulbright, R. K., \& Gore, J. C. (1995). Sex differences in the functional organization of the brain for language

Suominen, S., Helenius, H., Blomberg, H., Uutela, A., \& Koskenvuo. (2000). Sense of Coherence as a predictor of subjective state of health. Seminar 6. Retrived from http://www.kttl.helsinki.Fi/tero/posterit.htm.on 11 February 2017.

Tennant R., Hiller, L., Fishwick, R., Platt, S., Joseph, S., Weich, S., Parkinson, J., Seeker, J., \& StewartBrown, S. (2007). The Warwick-Edinburgh Mental Well-being Scale (WEMWBS): development and UK validation. Health and Quality of Life Outcomes.

Turner, L. H., \& Sterk, H. M. (1994). Differences that make a difference. Westport, Connecticut: Bergin \& Garvey Publishers

Vezina, M., Bourbonnais, R., Mare'riafM, A., \& Arcand, R. (2008). Stressau travail et sante mentale chez les adultesquebecois. Enquete sur lasante dans les collectivites canadiennes (cycle 1.2), Quebec, Canada:Institut de la Statistique du Quebec.

Wegner, M., Schwarzer, R., Jerusalem, M. (1981/1993). Generalized Self-efficacy Scale.In Schwarzer, R. (Ed.), Measurement of perceived self-efficacy. Psychometric scales for cross cultural research (pp. 1-25). Berlin 